\title{
Midsummer and Midwinter in the Rock Carvings of South Scandinavia
}

\author{
RICHARD BRADLEY \\ University of Reading
}

\begin{abstract}
The article considers the light shed on ancient religion by comparative linguistics and the analysis of visual images. Its starting point is the Bronze Age 'Sun Chariot' from Trundholm in Denmark, which is considered in both Flemming Kaul's book Ships on Bronzes and Martin West's Indo-European Poetry and Myth. The ideas of these two writers are discussed in connection with the evidence of prehistoric rock carvings in South Scandinavia. The article considers how such places were used and draws attention to the distinctive practice of depicting pairs of footprints in this medium. The footprints may mark the positions of people engaged in rituals at these sites, for in many cases the drawings are oriented towards the solstices. Perhaps these events were observed from the decorated outcrops. Although the field evidence is limited, it supports the idea of a solar cosmology postulated by Kaul and by West.
\end{abstract}

Keywords: Bronze Age, Scandinavia, rock carvings, cosmology, solstices, footprints

\section{Introduction: Ritual, Religion, Images and Texts}

The study of prehistoric religion poses a problem for archaeologists because it crosses the boundary between ancient rituals and beliefs. Not all rituals were directed towards the supernatural. Some were little more than a heightening of the conventions of daily life (Bradley 2005), but others could have taken place in special settings. They were performed on specific occasions, they were conducted by particular people, and they often employed unusual kinds of material culture. Colin Renfrew's book The Archaeology of Cult considers some of the elements shared between these public ceremonies, and their representation in the archaeological record (Renfrew 1995). 
The content of religious beliefs is harder for archaeologists to infer. Whilst it is possible to discuss the nature and organisation of rituals, there is little chance of identifying the doctrines they once expressed. In most cases that depends on the existence of literary evidence. There are two exceptions. One is where visual images survive and can be interpreted. The other is provided by comparative linguistics, a discipline which investigates the concepts shared between ancient languages, and the ways in which they were reflected in early written sources. Since those languages had a common ancestry, it is legitimate to infer that certain ideas had been widely distributed in the past. It is an approach that can easily be abused. One of the best examples of the linguistic method is Martin West's recent book, Indo-European Poetry and Myth (2007). It is revealing that a study of over 500 pages has only one illustration: the photograph on its cover. For the purposes of this paper it is still more striking that it is a picture of the Early Bronze Age 'Sun Chariot' from Trundholm, in Denmark. Here prehistoric archaeology and historical linguistics do converge.

\section{The Chariot of the Sun}

This remarkable object is relevant to West's thesis because it illustrates a number of ideas that seem to be expressed by Indo-European languages and texts. Sometimes the sun is considered as a wheel, rolling across the sky; often it is drawn by a horse (West 2007, 194-218). Still more important is the belief that the sun is illuminated as it travels from dawn to dusk, and presents its dark side during the night. It cannot be recognised as it returns to its point of departure. One possibility is that it is concealed under water; another that it is carried by a ship.

The Sun Chariot illustrates several of the same ideas. It consists of a bronze disc mounted on wheels, and is drawn by a horse, also on wheels. It can be viewed from two sides. When it appears to travel from left to right - the movement of the sun across the sky during the day - the disc is covered in gold. When it returns, from right to left (as it would do at night), the surface of the disc is plain.

The same distinction has been recognised by Flemming Kaul (1998) in a study of the decorated metalwork of Bronze Age Scandinavia. Among the commonest artefacts are the razors which were normally deposited with the dead. They feature tiny drawings of boats and the sun. Again the direction of travel is all-important. Where a ship carries the sun from left to right, it is associated with a horse. Kaul describes these vessels as 'day 
ships'. Where a boat is shown moving in the opposite direction, it is often accompanied by a fish or a snake. Kaul suggests that these pictures refer to the hours of darkness, and that while the sun returns from right to left it is hidden under water. In that case the crucial transitions occur at sunrise and sunset (Figure 1).

Kaul's reconstruction follows the conventional interpretation of the Sun Chariot. It is also consistent with West's account of Indo-European mythology, which is based on linguistic evidence. But here we have a problem. Is it possible to test this model using other kinds of archaeological evidence, or must it be accepted or rejected entirely on its own terms? In this article I suggest a possible solution.

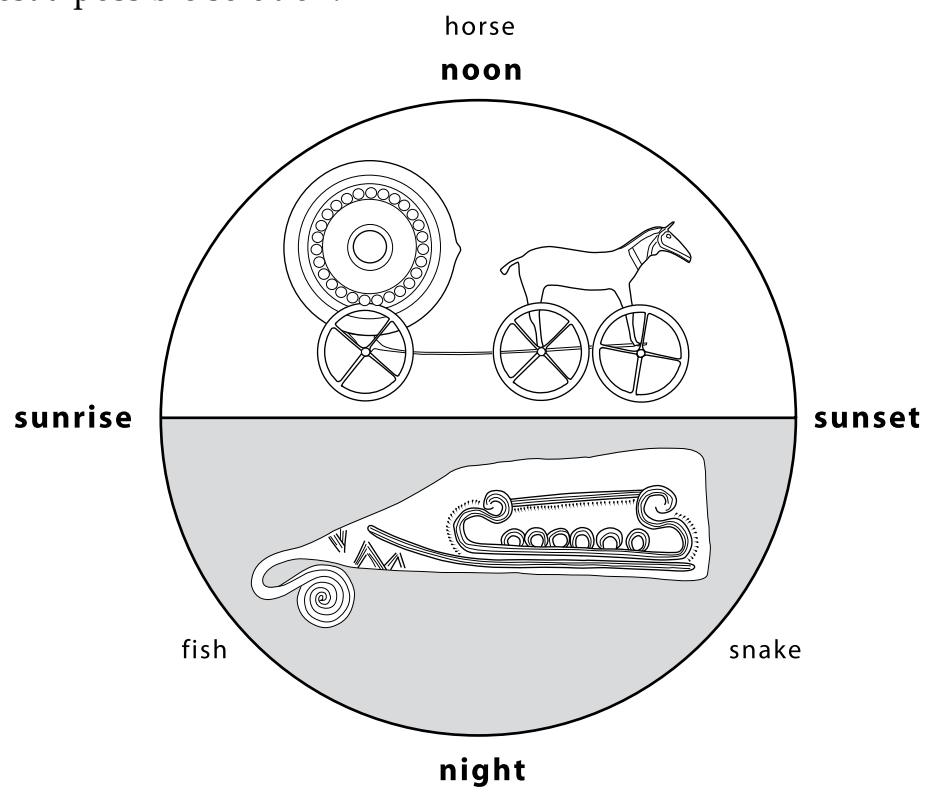

Figure 1. Outline of the solar cosmology postulated by Kaul (1998), with outline drawings of the Trundholm Sun Chariot and a decorated bronze razor from Denmark.

\section{South Scandinavian Rock Art}

Kaul has compared the designs on the decorated metalwork, which is commonest in Denmark and Southern Sweden, with those carved on rock outcrops during the Bronze Age (Kaul 2004). They are found in Denmark, but are more frequent in the south of Sweden and Norway. There are certain contrasts between these different media - in particular the importance of footprints among the carvings (Bradley 2006) - but perhaps the most per- 
suasive evidence is that many of the decorated rocks are beside the coast or lakes (Ling 2008). These are places where the sun would rise out of the water in the morning and set into its surface at night. Not surprisingly, such sites feature numerous drawings of ships. Quite different designs are found in landlocked areas.

Despite their different methodologies, Kaul and West agree that the movement of the sun was one of the basic concerns in the religious life of Bronze Age Scandinavia. It was associated with some fundamental beliefs. The disappearance and the reappearance of the sun might have stood for more basic ideas of death and regeneration (Bradley 2006). That would certainly explain why so many decorated artefacts were buried with the dead. At the same time, such questions would have been of particular importance in a region with striking differences between the seasons. At midwinter there were few hours of daylight, while in summer the sun was visible for long periods at a time. Such contrasts were vital to the wellbeing of crops and animals, so that the annual cycle could have been associated with ideas about fertility (Bradley 2006). Beliefs about fertility and death have always dominated interpretations of North European rock art (Almgren 1927; Kaul 2004), although the sun is less important in later Norse cosmology.

What has been lacking is evidence of the relationship between these schemes and the rituals that were performed in prehistory. Many of the decorated artefacts were used in funeral ceremonies, but is there any evidence of how the carved rocks were used? At present information is very limited. Burial cairns are often found near to the images and could have been associated with them, but the link has rarely been tested by excavation. Similarly, there is evidence that fires had been lit on some of the decorated outcrops, but it still has to be demonstrated that this happened during the Bronze Age.

\section{Footprints}

One widely distributed motif is rarely considered in accounts of Bronze Age rock art. It represents a pair of footprints - or, more exactly, two footsoles, since they show the outline of some kind of shoe (Figure 2). John Coles (1999) has made the interesting suggestion that they mark the positions of individuals standing on the rock. These people might have been highlighted like the actors on a stage.

The footprints are approximately life-size and are not connected with any of the human figures depicted on the same sites; those drawings are 


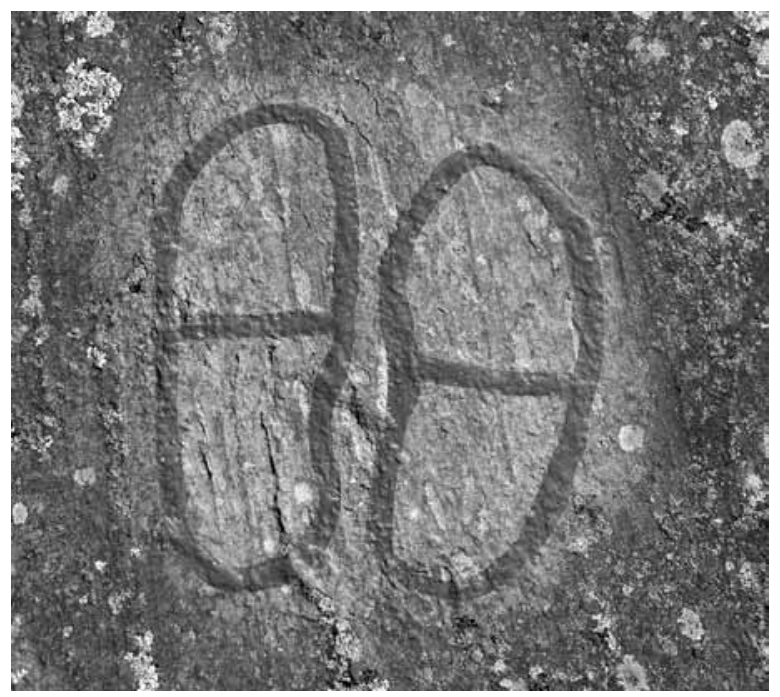

Figure 2. Carving of paired footprints at Himmelstalund, Sweden.

on a much smaller scale. The footsoles are similar to one another across the entire distribution of Scandinavian rock art, and it seems possible that they were based on the proportions of actual bodies. This raises an intriguing problem, for in that case they are likely to be those of young people rather than adults (Brox Nilsen 2005).

In other cases these images can be more schematic, extending from pairs of clearly separate footprints to curvilinear motifs in which they are run together. Since the shoe was held in place by a strap, the composite design looks rather like a circle bisected by two lines at right angles. It is difficult to tell it apart from the 'ring cross' that seems to represent wheels or the sun (Figure 3).

Perhaps this ambiguity was intended and the design was meant to suggest wider connections. At Trundholm the horse that draws the sun disc is mounted on wheels with four spokes; so is the disc itself. They look very like circular motifs in the rock carvings. The same applies to the carts depicted in Scandinavian petroglyphs, which can be mounted on wheels of exactly the same design. Other ring crosses are carried by boats. Were all these images connected by their reference to the sun?

If pairs of carved footprints could be run together so that they took a similar form to the ring cross, it is worth considering their significance in more detail. That is especially important when all these designs are found together. If the carved footsoles marked the positions of people standing 
on top of the rock, how were they related to ancient beliefs about the sun? Might they have been associated with rituals connected to its daily cycle, or could they have been more significant at the turning points of the year? It is necessary to study their orientations.

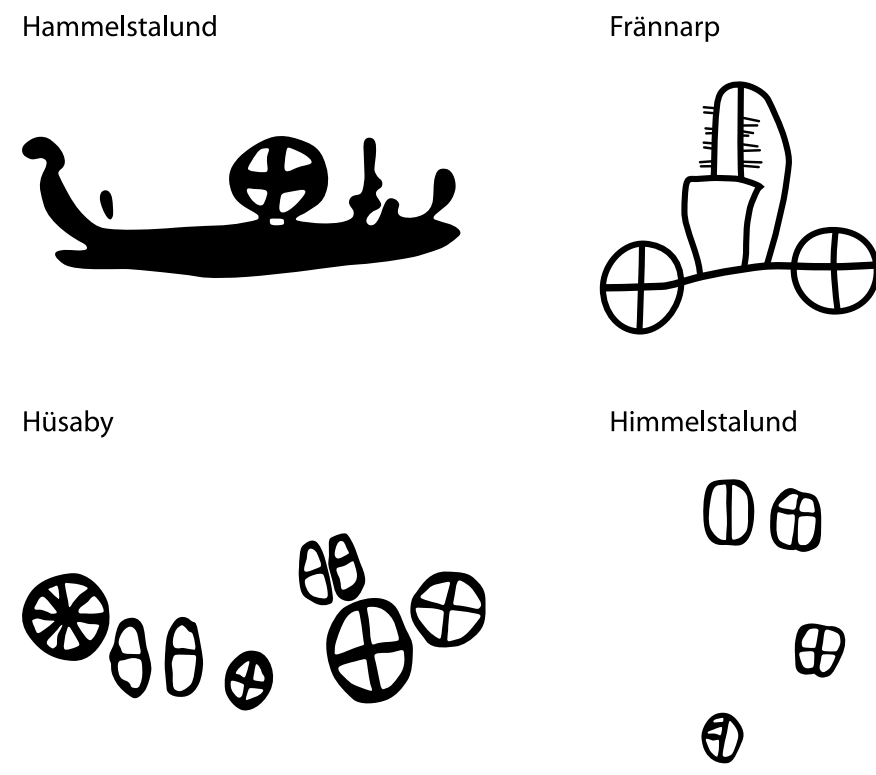

Figure 3. Overlap between drawings of 'ring crosses', possible sun symbols, wheels, and pairs of footprints in Swedish Bronze Age rock art. It suggests that these footprints may be connected with a solar cosmology. Information from Burenhult (1973).

\section{Sunrise, Sunset and the Passage of the Seasons}

Synnøve Vinsrygg (1980) has investigated the siting of rock carvings in southwest Norway, making the important point that they are oriented towards the south. At one of the most impressive sites, Revheim near Stavanger, the decorated outcrop commands a view of the sun at the midwinter solstice. Vinsrygg's observation is supported by another kind of evidence. Fett and Fett (1947) have published drawings of the petroglyphs in this region. They include a number of paired footprints. All the clearly identified examples face between southeast and southwest. Perhaps Coles was right to suggest that such images marked the positions of people standing on the decorated outcrops. If so, they might well have watched the movements of the sun. If the footprints really were those of young people, such observations could have happened during rites of passage. 
A more detailed pattern can be identified further to the south, although it can only be documented where illustrations of the rock carvings include a north point. That applies to Coles's accounts of decorated surfaces in Bohuslän, Østfold and south-west Uppland (Coles 2000, 2005), and to some of Goran Burenhult's records from eastern Sweden (Burenhult 1973); since he does not record the orientation of all the panels, his illustrations have not been used in compiling Figure 4, although they appear to support the trends identified in these other areas.

In two respects the evidence from these regions contrasts with the pattern identified in south-west Norway with its emphasis on views towards the south. Instead the orientations of the paired footprints cluster into three distinct groups, with possible indications of a fourth. The most frequent alignments were towards the northeast and northwest, with a slightly smaller group focusing on the southwest. A limited number of sites also emphasise the southeast. The most striking feature is that these distributions are discontinuous and seem to avoid other directions. In particular, the north is not represented (Figure 4).

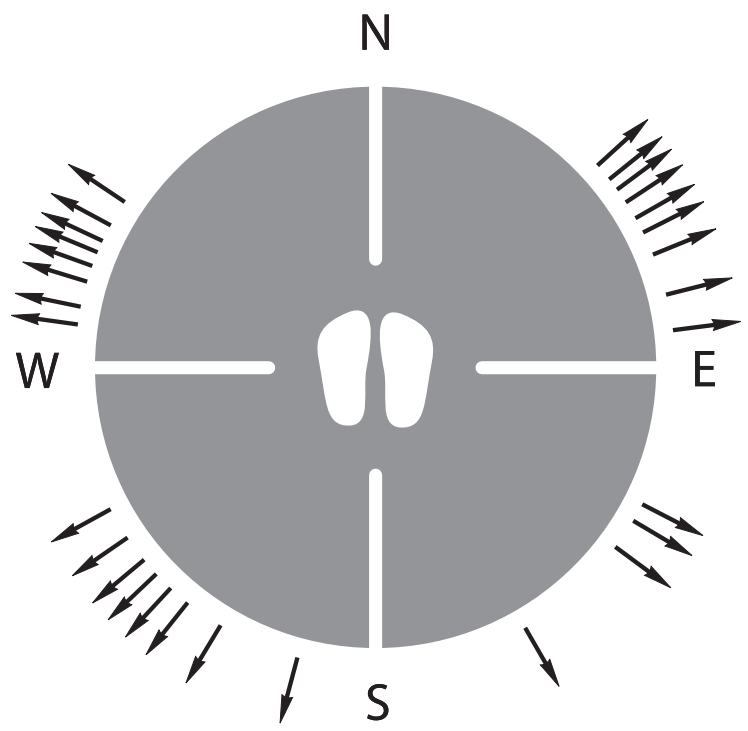

Figure 4. Orientation of carvings of paired footprints in Bohuslän and Uppland (Sweden) and Østfold (Norway). Information from Coles $(2000,2005)$. 
It is important to recognise that some of the carved rocks may have been inaccessible during the winter when they were hidden by snow. Others may have remained exposed because they were close to the sea. It is difficult to take this argument further, but it seems inescapable that these images would be easiest to identify during the warmer months, and it may have been then that most of them were used. This hypothesis is relevant because it was the time of year when the sun travelled furthest across the sky. In South Scandinavia it would have risen towards the northeast at the time of the midsummer solstice. It would have moved across the southern horizon until it set towards the northwest. That might account for the orientations of two of the groups of carved footprints. The smaller group which emphasises the southwest could have been directed towards the midwinter sunset. If so, the siting of the carved footprints might have indicated the positions of people who were observing the sun as it rose and set around the turning points of the year.

Such observations are both striking and unexpected, but it would be wrong to overemphasise their significance. They are relevant to sites in at least three regions, but the situation is quite different closer to the northern limit of this art style. At the same time, the scope of this analysis is limited by the sample of sites that have been published in a suitable form. In any case, drawings of pairs of footprints are commoner in some regions than in others.

One further consideration is important. These carvings do not have a precise alignment like the passage of a megalithic tomb, and this kind of study merely shows the general directions in which they are facing. That evidence is suggestive, but in order to identify more exact relationships with the position of the sun it would be necessary to record the profile of the horizon from each of these sites. To do so would require a substantial programme of fieldwork.

Despite these limitations, these rather distinctive rock carvings provide a new source of information to set alongside the studies of decorated metalwork by Kaul $(1998,2004)$. It complements the purely linguistic analysis provided by West (2007) and substantiates two of the key points in their interpretations. It supports their contention that the sun was one of the dominant elements in the Bronze Age cosmology of South Scandinavia. It also suggests a special interest in midsummer and midwinter, which were the pivotal points in the passage of the seasons. They may have played an important role in ancient rituals and beliefs as well. 
Bibliography

\section{Almgren Oscar}

1927 Hällristningar och kultbruk. Stockholm: Kungl. Vitterhets historie och antikvitets akademiens handlingar.

\section{Bradley, Richard}

2005 Ritual and Domestic Life in Prehistoric Europe. Abingdon: Routledge.

2006 Danish Razors and Swedish Rocks. Cosmology and the Bronze Age Landscape - Antiquity 80, 372-8.

\section{Brox Nilsen, Turid}

2005 Vedrørende en bergkunstlokalitet i Stjørdalen. Trondheim: Norges teknisknaturvitenskaplige universitet.

\section{Burenhult, Goran}

1973 The Rock Carvings of Götaland, Part 2. Lund: Acta Archaeologica Lundensia.

\section{Coles, John}

1999 The Dancer on the Rock: Record and Analysis at Järrestad, Sweden - Proceedings of the Prehistoric Society 65, 167-87.

2000 Patterns in a Rocky Land. Rock Carvings in South-West Uppland, Sweden. Uppsala: Department of Archaeology and Ancient History, Uppsala University.

2005 Shadows of a Northern Past. Rock Carvings of Bohuslän and Østfold. Oxford: Oxbow.

\section{Fett, Eva \& Per Fett}

1947 Sydvestnorske helleristninger. Rogaland og Lista. Stavanger: Stavanger Museum.

\section{Kaul, Flemming}

1998 Ships on Bronzes. A Study in Bronze Age Religion and Iconography. Copenhagen: National Museum.

2004 Bronzealderens religion: studier af den nordiske bronzealders ikonografi. København: Det Kongelige Nordiske Oldskriftselskab.

\section{Ling, Johan}

2008 Elevated Rock Art. Towards a Maritime Understanding of Rock Art in Northern Bohuslän, Sweden. Gothenburg: Gothenburg Archaeological Theses.

\section{Renfrew, Colin}

1995 The Archaeology of Cult. Athens: British School at Athens. 


\section{Vinsrygg, Synnøve}

1980 Om tidsaspekter i agrarristingane - Sverre Marstrander (ed.), Ristninger i forhistorie og middelalder, 37-62. (Varia 1.) Oslo: Universitets oldsakambing.

\section{West, Martin}

2007 Indo-European Poetry and Myth. Oxford: Oxford University Press. 